\title{
Tips for GP trainees working in obstetrics and gynaecology
}

Undertaking a rotation on obstetrics and gynaecology can be daunting. Many of you will not have had any experience of O\&G since a short block as a medical student 3 (or more) years ago. Be re-assured that you will not be expected to make decisions regarding methods of delivery. However, you will be expected to see pregnant women coming to the day assessment unit on labour ward, or in the early-pregnancy unit. Safe prioritising and approaching all new cases with history, examination, investigation, and senior help as required will enable you to deal with most scenarios. The single most important thing to do before starting is to become familiar with the local management guidelines of women less than 12 weeks pregnant who present with pain and/or vaginal bleeding.

O\&G can be emotionally demanding and pressurised at times. Try to find someone you can share your experiences with. If this is not possible within the O\&G department, talk to your educational supervisor. The skills learned in this rotation are invaluable for the GP to safely and effectively manage the women in their care. The following tips aim to help trainees enjoy their time in this specialty and gain as much useful experience as possible.

1. Prior to starting the attachment make a list of things you want to get out of it. Presenting this list to your clinical supervisor at the initial meeting shows you are organised and motivated to learn. Review the list regularly to make sure you are working through it.

2. If you are having problems speak to your clinical supervisor sooner rather than later.

3. Try to get on with the midwives as they can make your life much easier or much harder.

4. Ask senior midwives for help - they are very knowledgeable and experienced at managing most obstetric scenarios.

5. All women of childbearing age are pregnant until proven otherwise.

6. Remember to discuss contraception plans with all fertile patients. Remember to warn patients on oral contraception to take extra precautions while on antibiotics and to remind them that oral contraception does not protect them from sexually transmitted infections.

7. Before the start of your placement revise the signs, symptoms, and management of pre-eclampsia.

8. Prioritising is crucial when doing gynae - do not spend time seeing Early Pregnancy Assessment Clinic (EPAC) patients if someone is waiting in A\&E with a possible ruptured ectopic pregnancy.

9. Do not be afraid to ask for help.

10. When you get a referral from A\&E, ask them to do a urine dipstick (including $\beta \mathrm{HCG}$ ) while you are on your way.

11. Some A\&E departments will cannulate and do bloods for you (if you ask nicely).

12. If it's a long time since you passed a speculum try to refamiliarise yourself with the procedure prior to starting the attachment.

13. Always explain clearly to a patient what type of examination you are going to perform and gain informed consent before proceeding.

14. Always examine the abdomen before conducting a bimanual examination.

15. Always ask a patient to empty their bladder before conducting a bimanual examination.

16. When taking vaginal swabs, always take triple swabs (high-vaginal, endocervical and chlamydia).

17. Never conduct any sort of examination on a woman without a female member of staff present as a chaperone.

18. Always allow patients to undress and redress in private.

19. Get Directly Observed Procedural Skills (DOPS) in bimanual vaginal examination, smear taking and, if possible, Mirena ${ }^{\circledR}$ coil insertion.

20. Give pregnancy of unknown location (PUL) patients clear instructions if they are to be managed in the community. These instructions should preferably be written and detail what to look out for and when to return urgently, that is, if there is an increase in pain or heavy bleeding.

21. Beware the patient that has had a scan 'that showed everything was normal' if they don't have a copy of the report for you to read.

22. Abdominal pain and/or heavy PV bleeding in a woman of childbearing age is a ruptured ectopic pregnancy until proven otherwise.

23. Suspected ruptured ectopic is an emergency requiring cannula, bloods (including Group \& Save), prompt senior review and booking for theatre. Remember that these patients can seem well before decompensating rapidly.

24. If you are not happy counselling or performing terminations then let your supervisor know as soon as possible.

25. Try to spend time in clinics seeing common GP referrals, such as postmenopausal bleeding and dyspareunia.

26. Postmenopausal bleeding is cancer until proven otherwise.

27. Become familiar and fluent with EPAC management options, that is, expectant, medical and surgical management. At the beginning do not be afraid to ask for senior help.

28. Try to observe an Evacuation of Retained Products of Conception (ERPC) early in the rotation as it will make explaining the procedure to patients easier.

29. Try to remain compassionate in EPAC clinic even if it's the tenth patient you have seen that day. The way you handle their miscarriage will stay with them for life.

30. If you do take part in the pre-op assessment or performance of ERPC or termination procedures then make sure a 'sensitive disposal of fetal remains' form has been completed and signed by the patient.

31. When assisting caesarean sections, ask 
the surgeon what they expect you to do before the start of the operation.

32. Revise the management of postpartum haemorrhage before starting.

33. Do not discharge pregnant women with abdominal pain or PV bleeding without consulting a senior colleague first.

34. Remember that pregnancy is not an illness.

35. When faced with an obstetric emergency, call for help from the obstetric, anaesthetic, and paediatric teams and then remember Airway, Breathing and Circulation (ABC).

36. During the placement become familiar with normal vaginal deliveries.

37. Become confident at examining a pregnant woman's abdomen during your placement.

38. Never prescribe NSAIDs to pregnant women.

39. If unsure always check what you are prescribing is safe for pregnant/breastfeeding women as appropriate.

40. Consider sitting the Diploma of the Royal College of Obstetricians and Gynaecologists (DRCOG) during your placement as this will be the easiest time to sit it.

\section{Alexander Goodman and Matthew Burkes}

DOI: 10.3399/bjgp11X567324

\section{What is the collective noun for a group of patients?}

Every weekday lunchtime I have a scheduled telephone surgery. It sends the practice's phone bill skywards, but we accept most such calls nowadays are to mobiles as people are busy (or like to appear busy!). Despite this, up to a third of these consultations fail to take place. This is partly because one of our receptionists has a rather annoying habit of being one random digit out, in the given eleven. Other reasons we're told, include: batteries running low; bosses demanding they be switched off; or because our rolling southern Scottish landscape still has many 'blind spots.'

I therefore find myself each day listening to a robot curtly telling me to leave a message or to a pleasant local accent asking me to accept one's apologies. My 'message' I recently noticed is a little odd, suggesting I indeed called at the arranged time but as I have a 'wall of patients' for the rest of the afternoon it is unlikely I will be able to call back. Quite how I arrived at such a contrived construction cliché I have no idea, but it caused me to ponder on my reasoning and imagery. A wall suggests a homogenous, perhaps insurmountable, and featureless barrier to freedom. Many surgeries could legitimately be described thus but if a wall is an unsatisfactory term, what is the correct collective noun for a group of patients? A coffee-break search of the literature did not yield any accepted terms or any results at all so I offer you now some plausible possibilities.

An Expectation of patients. Increasingly, these expectations are unrealistically high and we are therefore bound to disappoint. Some chest physicians and other doctors may prefer the more offensive Expectoration of patients!

A Murder of patients. Stealing the term for a group of crows but may be more apposite for the unfortunate victims of Drs. Shipman and Bodkin Adams.

A Gaggle of patients. Another ornithological term but a Google would serve to remind us how well read our patients now consider themselves to be.

A Profit of patients might be how less scrupulous private practitioners view their clientele.

A Hospital of patients is, ironically, a bit sterile and as the tendency seems to be to empty beds as quickly as possible, a Discharge of patients would seem fitting. A Community of patients is worthy of consideration too as, by extrapolation, that is where all patients will soon reside. I also like an Infirmity of patients but this might be considered a little too submissive and lacking in patient empowerment (whatever that actually is!)

An Intolerance of patients nicely covers both the increasing demands and the plethora of allergies we now face in general practice. (Why not a Plethora: of classical origin and suitably ambiguous to lay personnel?)

A Concern and a Complaint of patients similarly have dual connotations; both negative and positive.

Patients and our relationships with them are ever-changing and I think a collective noun illustrating such fluidity would suit. Some practitioners may be fortunate enough to have a steady Trickle of patients on whom they can devote their attentions and skills but most are rather overwhelmed by a Tidal Wave or Deluge. But the term which for me best encapsulates the nature of my work, always too busy and struggling to stay afloat, is a Torrent of patients. It might be best that I don't use this phrase on the phone though!

\section{David Carvel}

DOI: 10.3399/bjgp11X567333 